\title{
UCRL-TR-224396
}

LA W RENCE LIVERMORE NATIONAL LABORATORY
A Study of the Structure and Metabolic Processes of a Novel Membrane Cytochrome in an Extreme Microbial Community

Stephanie E. Wong, Christopher Jeans, Michael $P$. Thelen

September 13, 2006 
This document was prepared as an account of work sponsored by an agency of the United States Government. Neither the United States Government nor the University of California nor any of their employees, makes any warranty, express or implied, or assumes any legal liability or responsibility for the accuracy, completeness, or usefulness of any information, apparatus, product, or process disclosed, or represents that its use would not infringe privately owned rights. Reference herein to any specific commercial product, process, or service by trade name, trademark, manufacturer, or otherwise, does not necessarily constitute or imply its endorsement, recommendation, or favoring by the United States Government or the University of California. The views and opinions of authors expressed herein do not necessarily state or reflect those of the United States Government or the University of California, and shall not be used for advertising or product endorsement purposes.

This work was performed under the auspices of the U.S. Department of Energy by University of California, Lawrence Livermore National Laboratory under Contract W-7405-Eng-48. 


\section{A Study of the Structure and Metabolic Processes of a Novel Membrane Cytochrome in an Extreme Microbial Community}

STEPHANIE E. WONG (University of California, Los Angeles, Los Angeles, CA, 90024)

CHRIS JEANS (Lawrence Livermore National Laboratory, Livermore, CA 94550)

MICHAEL P. THELEN (Lawrence Livermore National Laboratory, Livermore, CA, 94550)

UCRL-TR-224396

This work was performed under the auspices of the U.S. Department of Energy by University of California, Lawrence Livermore National Laboratory under Contract W-7405-Eng-48. 


\section{Table of Contents}

$\begin{array}{lc}\text { Abstract } & 1 \\ \text { Introduction } & 2 \\ \text { Materials and Methods } & 3 \\ \text { Results and Discussion } & 10 \\ \text { Conclusions } & 15 \\ \text { Acknowledgements } & 15 \\ \text { References } & 16 \\ \text { Figures } & 17\end{array}$




\begin{abstract}
The action of iron oxidizing microbes can generate acid mine drainage (AMD), characterized by acidic, toxic metal-tainted water that pollutes various water resources. The acidophilic biofilm community populating the Richmond mine, a pyrite $\left(\mathrm{FeS}_{2}\right)$ deposit in Northern California, is a key component of the oxidation of Fe(II) as well as subsequent pyrite dissolution. These natural biofilms contain many novel proteins that are being studied in order to understand how these microbes oxidize iron. The focus of this study is on the structure and characteristics of one novel, abundant outer membrane protein, cytochrome $572\left(\mathrm{Cyt}_{572}\right)$, which is perhaps important to the function of the entire community. To detect and study this cytochrome, monoclonal antibodies $(\mathrm{mAb})$ were produced and screened for specificity to $\mathrm{Cyt}_{572}$, both purified and membrane-bound. This was accomplished using enzyme linked immunosorbent assay (ELISA) and western blot analysis. Using western blotting, the presence of three high molecular weight bands at positions of dimer, trimer and tetramer corroborate chromatographic results that $\mathrm{Cyt}_{572}$ is a tetramer. Immunoprecipitation was used to detect a $\mathrm{Cyt}_{572}$ specific multiprotein complex, and these experiments are in progress. Apart from its novel amino acid sequence, $\mathrm{Cyt}_{572}$ binds to a heme group that exhibits unique spectral properties. To characterize the heme further, several biochemical methods were used to examine the purified cytochrome. Ethidium bromide was used in a novel way to detect proteins containing heme. The smallest heme-binding polypeptide fragment, about $23 \mathrm{kDa}$, was identified by gel electrophoresis after proteolytic digestion of purified $\mathrm{Cyt}_{572}$. The inability of these enzyme digests to completely degrade the protein reveals a secondary structure protective mechanism surrounding the heme group. This is perhaps associated with biofilm membrane proteins like $\mathrm{Cyt}_{572}$ that are in contact with an extremely acidic environment. Heme-protein interactions and higher order protein complexes have likely been selected for stability and the efficient transfer of electrons from $\mathrm{Fe}(\mathrm{II})$ to cells for energy, an essential function in the biofilm community.
\end{abstract}




\section{INTRODUCTION}

The unique microbial community found at the Richmond Mine, located near Redding,

CA, fosters a microbial biofilm that plays an important role in acid mine drainage (AMD).

Acidic water containing toxic metals flows through the $\mathrm{FeS}_{2}$ (pyrite) mine and drains into nearby

water sources. Without neutralization, AMD can potentially come in direct contact with local ecosystems, causing immense environmental harm over time.

Despite very acidic conditions, with $\mathrm{pH}$ values ranging from 0 to 1 , and high

temperatures between 40 to $50{ }^{\circ} \mathrm{C}$, microbial communities cultivate in numerous biofilms along the mine's pyrite-rich floors. These microbes are completely self-sufficient: they not only fix carbon and nitrogen from the air within the mine, but also derive electrons for energy from the oxidation of soluble $\mathrm{Fe}(\mathrm{II})$ in the mine drainage. The product of this reaction is $\mathrm{Fe}(\mathrm{III})$, which acts as a chemical catalyst for pyrite oxidation through the reaction:

$$
\mathrm{FeS}_{2}+14 \mathrm{Fe}^{3+}+8 \mathrm{H}_{2} \mathrm{O} \rightarrow 15 \mathrm{Fe}^{2+}+2 \mathrm{SO}_{4}{ }^{2-}+16 \mathrm{H}^{+}[1]
$$

This leads to the accumulation of sulfuric acid and the formation AMD. To understand the mechanisms by which these bacteria oxidize iron, the function and structure of several unique biofilm proteins are being studied. The model organism Leptospirillum group II is found in low $\mathrm{pH}$ environments and controls the rate of formation of AMD [2]. Leptospirillum has been shown to be a central member of the biofilm communities and its fully sequenced genome provides a foundation to identify novel proteins and define functions such as cell signaling, defense, heme-binding, and transport [3].

As key components of iron oxidation, our focus has been on proteins found in cellular membranes and near the surface of cells in the biofilm community. Previous research has shown that cytochromes important to redox reactions and electron transport are highly abundant 
throughout the biofilm and some of these proteins are linked to genes with unknown functions [3]. One of the most abundant proteins, cytochrome $572\left(\mathrm{Cyt}_{572}\right)$, is an outer membrane protein that is yellow-red in color and exhibits unusual heme group properties. Our work investigates Cyt ${ }_{572}$ 's sequence, secondary structure, and role in iron oxidation.

In this paper, we use various purification techniques, electrophoresis experiments, enzyme digests, mass spectrometry, and antigen-antibody interactions to characterize $\mathrm{Cyt}_{572}$.

\section{MATERIALS AND METHODS}

\section{Purification of Cyt ${ }_{572}$}

The cellular fraction containing $\mathrm{Cyt}_{572}$ from the $\mathrm{AB}$ Muck and C-Drift areas of the mine (Figure 1) were initially prepared by Steven Singer and Anna Siebers [4]. In order to neutralize the acidic solution of the cellular fraction samples, they were thawed on ice with the addition of $100 \mathrm{~m} M$ MES buffer (2(N-Morpholino) ethane sulfonic acid), $\mathrm{pH}$ 5. Washed biofilm was disrupted using a pestle/tube homogenizer and then lysed by sonication and multiple centrifugations in TE buffer, $\mathrm{pH} 7$ (10 $\mathrm{m} M$ Tris, $1 \mathrm{~m} M$ EDTA). The final centrifugation is carried out at 31,600 rpm $(100,000 \times \mathrm{g})$ for 1 hour, resulting in a tight, translucent reddish brown pellet of cell membranes. These were resuspended with some difficulty into the same buffer and stored at $4^{\circ} \mathrm{C}$. The clear, yellowish supernatant was concentrated down by resuspensions with the TE7 buffer followed by centrifugations. A detergent-compatible (DC) protein assay (Bio-Rad kit), was used to determine the concentrations of the samples following detergent solubilization. Gel filtration column chromatography on a SuperDex 200 Column (Amersham) was used to further purify proteins of different sizes. 
To prepare the sample for nucleic acid removal, a $100 \mu \mathrm{L}$ extract containing DM was desalted with $20 \mathrm{mM}$ Tris-HCL, $0.05 \% \mathrm{DM}$, in order to remove EDTA, which inhibits nuclease activity. DNase I (New England Biolabs), Micrococcyl nuclease (Sigma) and RNace-It Ribonuclease Cocktail (Stratagene) were prepared in appropriate reaction buffers in accordance with manufacturer's protocol, and another nuclease was prepared with a combination of DNAse I and RNace-It in the DNase I buffer. $5 \mu \mathrm{L}$ of Cyt $_{572}$ samples were incubated with $5 \mu \mathrm{L}$ of the appropriate reaction buffer and $1 \mu \mathrm{L}$ of each nuclease for 30 minutes at 37 degrees $\mathrm{C}$ and run on an agarose gel. The nuclease experiment was repeated at a later date with doubled volumes of $\mathrm{Cyt}_{572}$, reaction buffer, and enzyme. Half of these samples were prepared with a buffer exchange column followed by dialysis to remove EDTA and half with just dialysis so EDTA remained.

The DM extract with no EDTA and a sample of Fraction 2 (F2) from previous column chromatography were treated with and without Proteinase K (PK, in a 1:5 ratio of enzyme to protein) in order to find out if nucleic acid was actually in the sample. The samples were heated for an hour at $55^{\circ} \mathrm{C}$ followed by SDS-PAGE performed according to Laemmli [5]. The 10-20\% polyacrylamide gels were stained with ethidium bromide (EtBr) and SilverSNAP Stain Kit II (following the Pierce kit protocol) for comparison. The agarose gel and EtBr stained polyacrylamide were viewed under UV light for fluorescence. An EtBr stain was chosen for the fluorescence that it causes when bound to nucleic acid.

\section{Methods for Detecting and Isolating the Heme Group}

Heme group fluorescence in various proteins was investigated with EtBr staining. Samples of F2, cytochrome c and MES supernatant (MES S/N, both at $1 \mathrm{mg} / \mathrm{mL}$ ), and cytochrome 579 (Cyt 579 , at $2.5 \mathrm{mg} / \mathrm{mL})$ [6] were prepared with a few microliters of DTT (amount depending on the stock concentration of protein) and $10 \mu \mathrm{g}$ of protein per lane were 
separated on 10-20\% polyacrylamide gels. The gels were stained with EtBr and the Imperial Protein Stain kit from Pierce Biotechnology as described by the manufacturer.

In order to determine the intensity of fluorescence at various concentrations, bovine serum albumin and cytochrome $\mathrm{c}$ (both at 1,2 , and $5 \mu \mathrm{g}$ per lane) were analyzed on 10$20 \%$ polyacrylamide gels. The degree of fluorescence was determined through EtBr and Imperial Protein staining and viewing under UV light.

To test for the minimal heme binding unit liberated by protease activity, $5 \mu \mathrm{L}$ of $\mathrm{Cyt}_{572}$ was treated with and without $1 \mu \mathrm{L}$ of either PK or trypsin. The samples were incubated as indicated below, then separated on 10-20\% polyacrylamide gels and stained with EtBr and silver. Digest 1: Trypsin

Samples of Cyt 572 (at $1 \mathrm{mg} / \mathrm{mL}$, a total of $10 \mu \mathrm{g}$ per lane) were prepared, including one with trypsin (stock solution from Pierce). The trypsin sample was incubated at $37^{\circ} \mathrm{C}$ for an hour. A separate sample of cytochrome c was made at $0.5 \mathrm{mg} / \mathrm{mL}$ to check for heme stain effectiveness and $6 \mu \mathrm{g}$ of this was loaded in the gel. $5 \mu \mathrm{L}$ of $5 \mathrm{x}$ Lane Marker Non-Reducing Sample Buffer (Pierce) was added as a loading buffer to each sample and was followed by incubation for $5 \mathrm{~min}$ at $95^{\circ} \mathrm{C}$ before loading. The protein was separated with SDS-PAGE on 10$20 \%$ polyacrylamide. One gel was stained with silver stain and the other with a heme stain protocol from Francis and Becker [7] which made heme-binding fragments visible.

\section{Digest 2: Trypsin Time Profile}

A repeat trypsin digest was performed utilizing a time course for the digestion of the protein. The digest was performed with $10 \mu \mathrm{g}$ of protein per lane for $2,4,6,8$, and 24 hours at $37^{\circ} \mathrm{C}$. A $5 \mu \mathrm{L}$ solution of the loading buffer (used in the previous trypsin digest) as well as incubation at $4^{\circ} \mathrm{C}$ was used to stop the reaction at the various time points. The same cytochrome 
c sample was used for the heme stain. SDS-PAGE on $10-20 \%$ polyacrylamide was used to analyze the digest. This digest was stained according to the same protocol as used in Digest 1.

\section{Digest 3: Proteinase K}

Purified Cyt $t_{572}$ samples (F2) were diluted with TE7 buffer and 2x PK buffer $(20 \mathrm{mM}$ Tris-HCL $\mathrm{pH} 8,10 \mathrm{mM} \mathrm{CaCl} 2$, and $1 \% \mathrm{SDS}$ ) and incubated with the PK enzyme [8] at $55^{\circ} \mathrm{C}$ for an hour. Prior to loading, $5 \mu \mathrm{L}$ of the $5 \mathrm{x}$ sample buffer was added to each sample and all samples were heated at $95^{\circ} \mathrm{C}$ for 5 minutes. $10 \mu \mathrm{g}$ of protein were loaded per lane in $10-20 \%$ polyacrylamide gels, followed by Silver and heme staining.

\section{Digest 4: Time Profile of Proteinase K}

A time course spanning an hour was designed for cytochrome samples with and without SDS. Samples included $10 \mu \mathrm{g}$ of protein per lane and were diluted with TE7 buffer and 2x PK buffer. $1 \mu \mathrm{L}$ of PK was added for $1,3,5,10,30$, and 60 minutes. The samples were incubated at $55^{\circ} \mathrm{C}$ for the amount of time specified by each time point. The reaction was stopped at the time points with $0.1 \mu \mathrm{L}$ of $100 \mathrm{~m} M$ PMSF. Samples were prepared with loading buffer and heated according to the previous PK digestion experiment. After the samples were separated with the SDS-PAGE protocol, both gels were heme stained for analysis.

The PK time course experiment was repeated with additional PK added during the time course. Samples of cytochrome were prepared using the same protocol as the first PK time course. The samples were incubated with the initial volume of PK for 1 and 30 minutes, immediately followed by an additional $6 \mu \mathrm{L}$ of PK for 1, 30, and 60 minutes. The same PMSF stop solution was used. Samples were prepared with loading buffer, heated, and separated by SDS-PAGE and stained according to the previous PK time course. 


\section{Digest 5: Trypsin and Proteinase K Digest.}

Samples were prepared with $10 \mu \mathrm{g}$ of $\mathrm{Cyt}_{572}$ per lane. Sample 1 was the control with no enzyme, sample 2 was treated with a 24 hour trypsin digest, and sample 3 was incubated with a combination of the trypsin digest as well as a PK digest ( $1 \mu \mathrm{L}$ of PK per gel) for 30 minutes. Loading buffer was added to the three samples and they were heated and separated by SDSPAGE according to the previous PK time course experiments. A heme and silver stain were used following electrophoresis.

\section{Proteinase K Digest for N-Terminal Sequencing}

For N-terminal analysis of the heme binding fragment, $3 \mu \mathrm{L}$ of PK enzyme was added to $50 \mu \mathrm{g}$ of $\mathrm{Cyt}_{572}$ and incubated at $55^{\circ} \mathrm{C}$ for 30 minutes. The samples were heated for $5 \mathrm{~min}$ at $95^{\circ} \mathrm{C}$ along with $5 \mu \mathrm{L}$ of the $5 \mathrm{x}$ sample buffer and then were divided into 3 lanes on a $10-20 \%$ polyacrylamide gel by SDS-PAGE. After the initial gel electrophoresis, the gel was blotted to a Millipore Immobilon-P polyvinylidene fluoride (PVDF) membrane and the heme-binding bands were excised and sent to Columbia University Protein Core facility for N-terminal sequencing.

\section{High Concentrations of Cyt 572 for Tetramer Detection}

Cyt $t_{572}$ was prepared with the $5 \mathrm{x}$ sample buffer and heated for 5 min at $95^{\circ} \mathrm{C} .20,40$, and $80 \mu \mathrm{g}$ of protein were each loaded into separate lanes on $10-20 \%$ polyacrylamide gels. After electrophoresis, the gels were stained with a heme stain and GelCode Blue stain (Pierce), a coomassie stain to allow for mass spectrometry analysis.

\section{Preparation of mAbs and Screening by ELISA}

Protein from membranes (see Purification of $C y t_{572}$ ) was prepared as antigen and taken through the standard laboratory protocol for monoclonal antibody $(\mathrm{mAb})$ production. After 
selection by growth of hybridoma colonies, several ELISA titrations were performed to test for the strength of $\mathrm{Cyt}_{572}$-specific mAbs. The wells of the microplate (NUNC MaxiSorp 96-well plates) were coated overnight with Cyt $\mathrm{Ct}_{572}$ (stock concentration of $3 \mathrm{mg} / \mathrm{mL}$ ). $0.5 \mu \mathrm{L}$ of protein per well was used, diluted in a carbonate coating buffer, $\mathrm{pH} 9.6$, in order to coat $100 \mu \mathrm{L}$ per well. After washing twice with $1 \mathrm{x}$ TTBS, a blocking buffer of $0.5 \%$ BSA/PBS- $0.05 \%$ Tween 20 was added and the plate was incubated at room temperature for an hour. The primary antibody was applied to the coated plate following dilutions in the blocking buffer. After incubation on a shaking platform for an hour at $37^{\circ} \mathrm{C}$, the plate was washed and the binding of the $\mathrm{Cyt}_{572} \mathrm{mAbs}$ were revealed with the Bio-Rad goat anti-mouse $(\mathrm{H}+\mathrm{L})$ alkaline phosphatase conjugate diluted 1:1500. Sigma 104 phosphatase substrate (at a concentration of $2 \mathrm{mg} / \mathrm{mL}$ in a carbonate buffer) was used to reveal the enzyme conjugate. Results of the binding were detected at $405 \mathrm{~nm}$ with a plate reader (BioTek Synergy HT) after 10 and 30 minutes of incubation with the substrate. Positive readings (Abs $>0.2$ ) determined which $\mathrm{mAbs}$ were later used to probe the cytochrome during western blotting.

\section{Western Blot}

Protein fragments were probed with Cyt $_{572}$-specific antibodies in our western blots. $70 \mu \mathrm{g}$ of $\mathrm{Cyt}_{572}(3 \mathrm{mg} / \mathrm{mL})$ were divided into 7 lanes and separated with SDS-PAGE on 10-20\% polyacrylamide gel. Protein fragments were transferred onto a PVDF membrane and the membrane was blocked overnight with $5 \%$ dry milk/TTBS at 4 degrees $\mathrm{C}$. The primary antibody incubation was prepared with $500 \mu \mathrm{L}$ of each clone's media in $10 \mathrm{~mL}$ of $2 \%$ dry milk/TTBS. After an hour of incubation and shaking at room temperature, the secondary antibody, a 1:2000 dilution of horseradish peroxidase-conjugated goat anti-rabbit (Amersham), was applied to the membrane in $2 \%$ dry milk/TTBS. The membrane was incubated for an hour on a shaking 
platform and then washed twice with 1x TTBS and once with 1x TBS. Detection of conjugatedperoxidase activity was carried out with the Pierce substrate kit (SuperSignal West Pico Chemiluminescent Substrate) and visualized by chemiluminescent analysis. An alkaline phosphatase substrate (Bio-Rad) was also used in another western blot, at a 1:1500 dilution for colorimetric analysis.

\section{Immunoprecipitation}

Antibodies are prepared for immunoprecipitation (IP) by slowly adding $50 \%$ ammonia sulfate to the harvested media (harvested the media of clones 323-1, 55-1, and 161-2). The solution is stirred for an hour at $4^{\circ} \mathrm{C}$. Following centrifugation at 10,000 rpm for 40 minutes at $4^{\circ} \mathrm{C}$, the pellet is washed with $50 \%$ saturated ammonia sulfate in $1 \times$ PBS. The pellet is resuspended with $10 \mathrm{~mL}$ PBS and dialyzed in a surrounding solution of PBS/0.02\% azide overnight. The mAbs are filtered with a $5 \mu \mathrm{L}$ filter and run on a Protein A column-FPLC $(2 \mathrm{~mL}$ per fraction). In order to decrease background, the cell lysate (prepared according to $\mathrm{Cyt}_{572}$ purification techniques above and consisting of the proteins to be probed) is pre-cleared by adding True Blot anti-mouse IgG IP beads to the lysate. This solution is incubated on ice for 30 minutes then centrifuged at $10,000 \times \mathrm{g}$ for 3 minutes. The supernatant from the solution is incubated with the primary antibody on ice for an hour to allow antibody-antigen complex formation. After incubation, the same incubation and centrifugation techniques are used from the steps above to precipitate the complex of interest with an insoluble antibody protein such as Protein A. Following washing of the pelleted beads with a lysis buffer, the supernatant can be analyzed by SDS-PAGE and on a PVDF membrane after transfer. Using the laboratory western blot protocol for the chemiluminescent HRP substrate, complexes can be detected when a different antibody is used to probe for interaction with the antigen. 


\section{RESULTS AND DISCUSSION}

Purification of Cyt ${ }_{572}$ from Biofilm

In order to isolate a pure sample of $\mathrm{Cyt}_{572}$ for immunology and biochemistry experiments, membranes were prepared from AB Muck and C-Drift biofilms. Proteins were then extracted with detergent and fractionated by size exclusion column chromatography. Analysis of proteins separated by SDS-gel electrophoresis and silver staining indicated the major $57 \mathrm{kDa}$ heme-

containing protein, $\mathrm{Cyt}_{572}$, as well as an unknown $9 \mathrm{kDa}$ weight species (Figure 2). To determine whether this low molecular weight (MW) band was due to nucleic acid contamination, agarose gel electrophoresis was used to separate protein and nucleic acid for fluorescent staining. Three different nucleases, selected for activity with a wide-range of common nucleic acids, were utilized in the attempt to remove suspected nucleic acid in the sample. However, after gel electrophoresis, no smaller MW bands were detected, as would be expected with normal nuclease cleavage.

Using UV light to activate EtBr staining, fluorescence indicated nucleic acid was present in our samples. The gels exhibited equal fluorescence in both proteinase $\mathrm{K}(\mathrm{PK})$ and non-PK treated lanes, demonstrating that the fluorescence was a result of some type of nucleic acid and not protein. Since the low MW, tightly folded transfer RNA or ribosomal RNA species are more resistant to nuclease degradation than other nucleic acids, it is possible that the fluorescence in these samples is due to small RNAs.

\section{Methods for Heme Group Detection and Isolation}

A reverse experiment was performed by using PK to remove the protein and leave behind the nucleic acid, as opposed to cleaving nucleic acid from the samples. PK is a non-specific serine protease that cleaves at the carboxylic sides of aliphatic, aromatic or hydrophobic amino 
acids. Normal PK activity cleaves all protein and leaves only non-protein compounds intact, for example, the nucleic acid. PK was incubated with $\mathrm{Cyt}_{572}$ and stained with $\mathrm{EtBr}$ to analyze fluorescence. The sample without PK had a band which fluoresced at a position of $\sim 54 \mathrm{kDa}$ (Cyt 572 is $\sim 57 \mathrm{kDa}$ ) and a lower band located between $10-15 \mathrm{kDa}$; on the contrary, in the PK treated sample, the lower band appeared but not the main band at $54 \mathrm{kDa}$. The sample with PK did not show a band of the PK enzyme in the sample ( 29 kDa) when silver stained, which suggests complete autolysis of PK and perhaps incomplete digestion of $\mathrm{Cyt}_{572}$ as well. Unexpectedly, EtBr stained the $54 \mathrm{kDa}$ band, which we know to be $\mathrm{Cyt}_{572}$. EtBr is used to stain nucleic acids by insertion of the stain between the bindings of base pairs in a double helix [8] and has not been shown to bind heme groups in researched literature. It is possible that the novel heme group in $\mathrm{Cyt}_{572}$ binds EtBr using an unknown mechanism.

Other heme group proteins were prepared in order to compare them to Cyt ${ }_{572}$ stained with EtBr. Samples of $\mathrm{Cyt}_{572}, \mathrm{Cyt}_{579}$, cytochrome c, and MES supernatant were analyzed following electrophoresis with the same EtBr stain protocol as in the PK experiment. Under UV light, the gel illustrated that the heme groups had been stained by EtBr (see Figure 3b), which could indicate binding of the stain between the protein and its heme group.

Since both heme and non-heme group proteins showed some degree of fluorescence with the EtBr stain (Chris Jeans' previous work), the intensity of fluorescence was investigated by varying concentrations of BSA and cytochrome c. However, EtBr stain results showed poor staining. BSA bands were indistinguishable in the gel and cytochrome $\mathrm{c}$ bands had insignificant intensity differences. While the unusual $\mathrm{EtBr}$ staining heme group results were interesting, they appear inconclusive and were set aside for future analysis. 
In an effort to isolate the heme group of $\mathrm{Cyt}_{572}$ and further characterize its structure and function in iron oxidation, we used trypsin, a serine protease which cleaves at the carboxyl side of lysine and arginine, except when either is followed by proline. It was chosen due to its selectivity of cleavage sites which could be applied to the known $\mathrm{Cyt}_{572}$ sequence in order to determine the size of the heme-binding fragment. In Digest 1, trypsin was incubated with $\mathrm{Cyt}_{572}$ and the digest was analyzed with silver stain (Figure 4a) and a heme stain (Figure 4b). In Figure $4 \mathrm{~b}$, the untreated lane showed a single band positioned at $\sim 57 \mathrm{kDa}$ while the sample treated with trypsin was degraded compared to the control. It was a partial digest, as trypsin left a portion of the $57 \mathrm{kDa}$ band intact. We observed multiple heme staining lanes in the trypsin digest, with bands ranging from about 10 to $50 \mathrm{kDa}$. Had trypsin completely cleaved the protein at all the appropriate sites, bands $<7 \mathrm{kDa}$ would have been visible. The cytochrome c sample showed a free heme group low on the gel when stained with a heme stain, indicating the heme stain's accuracy. Silver stain was used for comparison against the heme-binding fragments in the heme stain.

The trypsin digest was attempted again utilizing a time profile (Figure 5a, Digest 2) because the first digest was not to completion. The heme stain in Figure $5 \mathrm{~b}$ showed a greatly increased digest of heme-binding fragments between 8 and 24 hours of incubation. Fragments $>26 \mathrm{kDa}$ seen in Digest 1 were degraded by the 24 hour time point. Lower MW bands were seen at $<14 \mathrm{kDa}$ on the silver stain (Figure 5a); however, since there are no Silver markers below 14.4 $\mathrm{kDa}$, the sizes of these bands could be inaccurate. Above the main $57 \mathrm{kDa} \mathrm{Cyt}_{572}$ band, three high MW bands at sizes of 115, 172.7, and $229 \mathrm{kDa}$ were visible in the control lane (Figure 5a) at positions of dimer, trimer, and tetramer. These results are consistent with the chromatographic results that show $\mathrm{Cyt}_{572}$ as a tetramer. 
High concentration samples were used to determine if $\mathrm{Cyt}_{572}$ existed as a tetramer following Digest 2. The 20,40, and $80 \mu \mathrm{g}$ concentrations were visible in the GelCode Blue stain at approximately the same location as previously observed. The bands were excised and sent to Mass Spectrometry for analysis and matching to $\mathrm{Cyt}_{572}$ 's sequence. Results from Mass Spectrometry are pending.

To facilitate complete digestion of $\mathrm{Cyt}_{572}, \mathrm{PK}$ was used in Digest 3. Silver and heme stains were applied following electrophoresis and are pictured in Figures $6 a$ and $b$. In the heme stain, we saw four discrete bands in the PK treated lane, all $<31 \mathrm{kDa}$. This was unexpected because PK is a non-discriminating protease that should cleave everything but the heme group and its motif. No PK band ( $29 \mathrm{kDa})$ was visible in the silver stained gel, which signified that PK had undergone complete autolysis and perhaps was not able to finish digesting the $\mathrm{Cyt}_{572}$ sample. The $+\mathrm{PK}$ lane displayed discrete bands on the gel, indicative that certain fragments of the protein were not cleaved at all. Since $\mathrm{Cyt}_{572}$ was not completed degraded by the protease, it is possible that the secondary structure of the protein offers some type of protection for the novel heme group.

To further study this predicted protective structure, a PK time profile (Digest 4, Figure 7) was designed parallel to the trypsin time profile. This initial digest was performed in order to determine the duration of a PK digest of $\mathrm{Cyt}_{572}$, which was found in Figure 7 to end after approximately 10 minutes. Figure 7 shows a $23 \mathrm{kDa}$ band believed to be the smallest hemebinding fragment. This band is significantly darker than other bands in the digest and is also visible in Figure 5b, 6b, and 8. In the following experiment, a PK time profile was conducted by adding more protease after 30 minutes to compensate for the autolysis shown to occur within the first 10 minutes. As seen in the heme stain in Figure 8, the additional PK failed to digest the 
protein any further. These results corroborate the previous PK digest results (Digest 3) that perhaps a protective mechanism exists that encompasses the heme group in the secondary structure of $\mathrm{Cyt}_{572}$. This structure may allow the microbes to exist in extremely acidic conditions and explain the mechanisms used to oxidize Fe(II).

Figures $9 \mathrm{a}$ and $\mathrm{b}$ show the results of the fifth digest, which utilized a combination of trypsin and PK in an attempt to further digest $\mathrm{Cyt}_{572}$. One sample was incubated with trypsin for 24 hours, while the other sample had an additional volume of PK added after 30 minutes following the trypsin digest. Despite detergent streaking, both the Silver and heme stained gels showed increased digestion with the trypsin and PK digest that was not seen with the individual proteases. However, a discrete band just below $31 \mathrm{kDa}$ in Figure 8a did remain, as well as a series of lower MW bands $<21 \mathrm{kDa}$. While the combination of trypsin and PK did increase digestion compared to previous digests, we were unable to digest $\mathrm{Cyt}_{572}$ completely, which is consistent with the results suggesting a protective structure.

\section{$N$-Terminal Sequencing Results}

$\mathrm{N}$-terminal sequencing results are pending.

\section{Monoclonal Antibody Recognition of Cyt $t_{572}$}

ELISA was used to establish the binding capacity of $\mathrm{Cyt}_{572}$-specific antibodies. mAb clone \#323-1 exhibited strong binding to the antigen. This clone was then used to probe $\mathrm{Cyt}_{572}$ by western blotting. Western blot results with an alkaline phosphatase substrate showed the three bands above the $57 \mathrm{kDa} \mathrm{Cyt}_{572}$ band, approximately the same sizes as calculated with Digest 2 . This confirms that the bands are from the $\mathrm{Cyt}_{572}$ tetramer since the antibodies used in the western 
blot were made using $\mathrm{Cyt}_{572}$ as the antigen. IP experiments are in currently progress and results are pending.

\section{CONCLUSIONS}

Our studies point to $\mathrm{Cyt}_{572}$ and its novel heme group as essential components in iron redox reactions and are crucial to understanding the function of this extreme microbial community. A $9 \mathrm{kDa}$ species that co-purified with $\mathrm{Cyt}_{572}$ exhibits properties similar to a small RNA species, based on EtBr staining and absorbance at 260nm. During these experiments, it became evident that EtBr also caused heme containing proteins to fluoresce with intensity somewhat greater than other proteins. In solution, $\mathrm{Cyt}_{572}$ likely exists as a tetramer, initially indicated by chromatographic results. Moreover, separation by SDS-gel electrophoresis followed by silver staining and immunoblot analysis indicated three bands at 115, 172.7, and $229 \mathrm{kDa}$, suggesting strong self association in $\mathrm{Cyt}_{572}$ even in the presence of SDS. Using proteolytic digestion, a $23 \mathrm{kDa}$ heme-binding fragment was identified. The failure of proteases to digest Cyt $_{572}$ completely is perhaps indicative of a secondary structure protective mechanism that encompasses the heme group and may contribute to the overall stability of the protein, enabling it to function in close proximity to the extremely acidic conditions.

\section{ACKNOWLEDGEMENTS}

This research was conducted in the summer of 2006 at Lawrence Livermore National Laboratory with funding from the U.S. Department of Energy. Special thanks to my mentor, Michael P. Thelen, for his expertise, guidance, and for giving me such an amazing opportunity and learning experience. I thank Chris Jeans, my daily mentor in the laboratory, for his patience 
and for sharing his knowledge with me. I would also like to thank Steven Singer and Mona Hwang for all their advice, instruction, and humor.

\section{REFERENCES}

[1] D. K. Nordstrom and G. Southham, in Geomicrobiology: Interactions Between Microbes and Minerals, J. F. Banfield and K. H. Nealson, Eds. (Mineralogical Society of America, Washington, DC, 1997), vol. 35, pp. 361-390.

[2] M.O. Schrenk, K.J. Edwards, R.M. Goodman , R.J. Hamers , J.F. Banfield, "Distribution of Thiobacillus ferrooxidans and Leptospirillum ferrooxidans: Implications for Generation of Acid Mine Drainage,’ Science, vol. 279, no. 5356, Mar., pp. 1519-1522, 1998.

[3] M.P. Thelen, "Biofilm Proteins Associated with Acid Mine Drainage," [PowerPoint Presentation] June 20, 2006. Presented at Lawrence Livermore National Laboratory.

[4] A. Siebers, S. Singer, M.P. Thelen, "Analyzing the Structure and Function of Proteins within a Unique Microbial Community," submitted Aug. 2006.

[5] U.K. Laemmli, "Cleavage of structural proteins during the assembly of the head of bacteriophage T4,” Nature, 227: 680-685, 1970.

[6] S. Singer (2006, July 26). Understanding Natural Microbial Communities Using Proteogenomics and Biochemistry. Presented at the Annual Biosciences Directorate Postdoctoral Symposium, Lawrence Livermore National Laboratory.

[7] R.T. Francis and R.R. Becker (1984) Anal. Chemistry 136, 509-14.

[8] W. Ebeling, N. Hennrich, M. Klockow, H. Metz, H. Orth. D., and H. Lang. "Proteinase K from Tritirachium album Limber," (1974) Eur. J. Biochem. 47, 91-97.

[9] A. Vincent and K. Scherrer, "A Rapid and Sensitive Method for Detection of Proteins in Polyacrylamide SDS gels: Staining with Ethidium Bromide," Mol Biol Rep., 31;5(4): 209-14, 1979. 


\section{FIGURES}

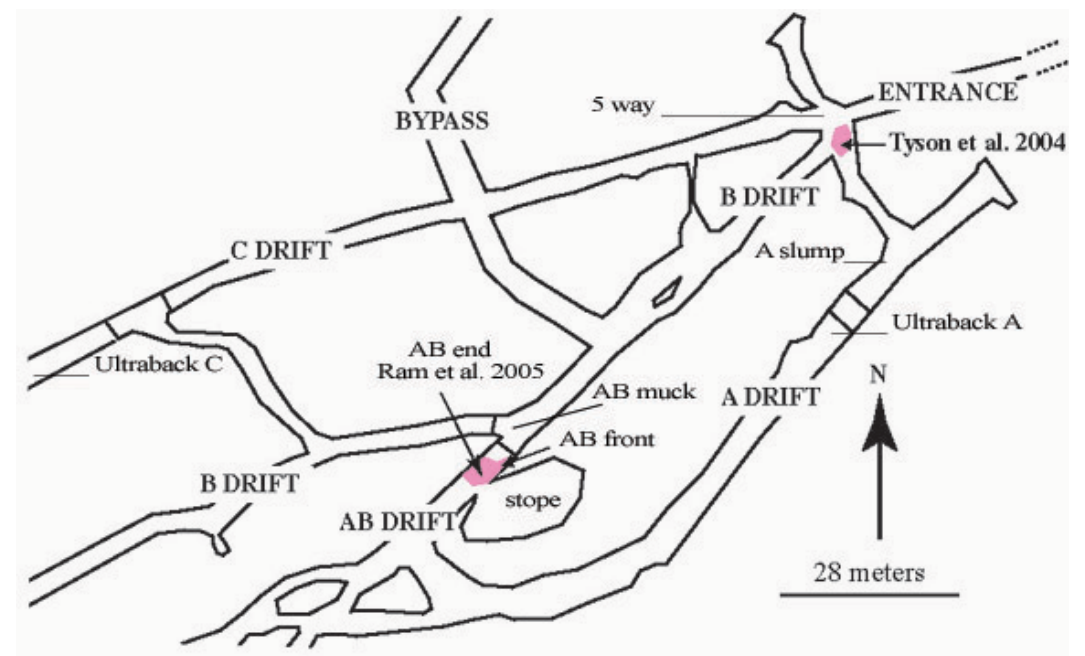

Figure 1. Map of Iron Mountain Mine field site used in this research.

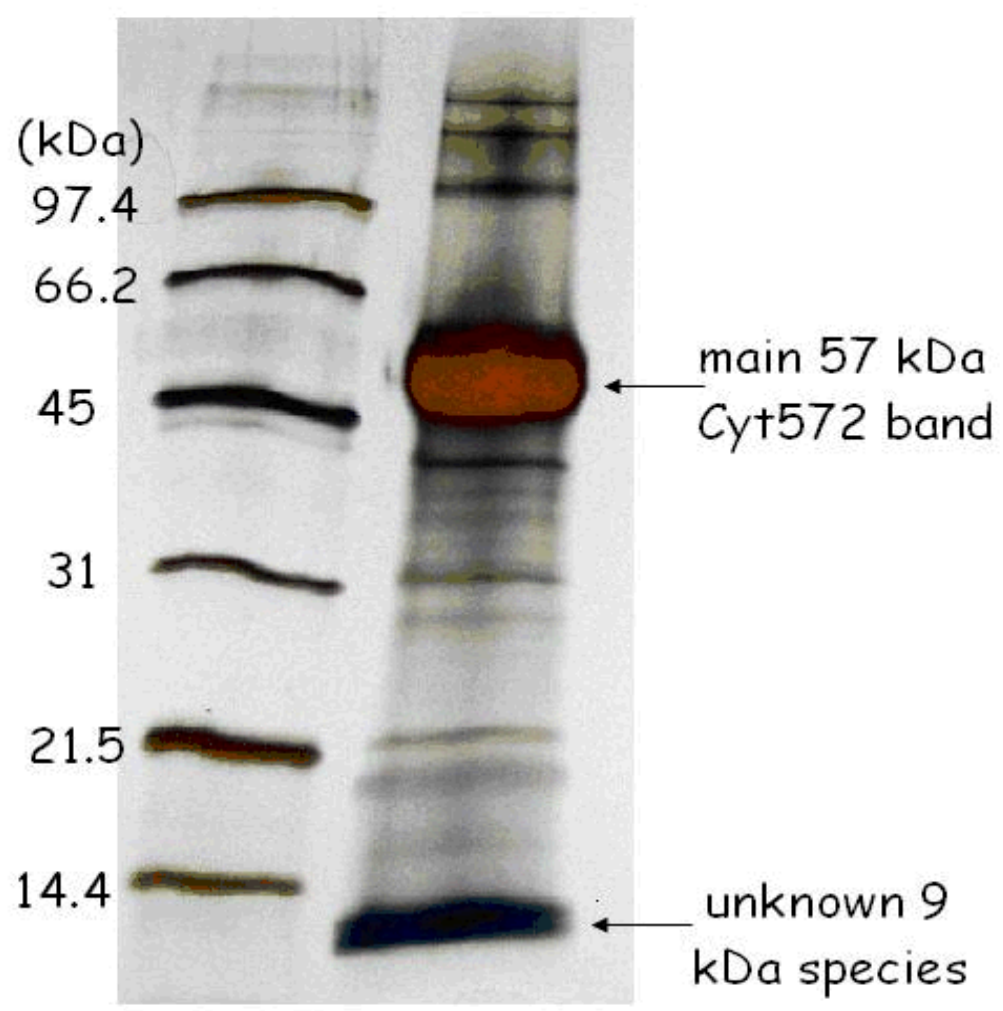

Figure 2. Silver stained $10-20 \%$ polyacrylamide gel showing $\mathrm{Cyt}_{572}$ and the $9 \mathrm{kDa}$ band from Fraction 2 . 


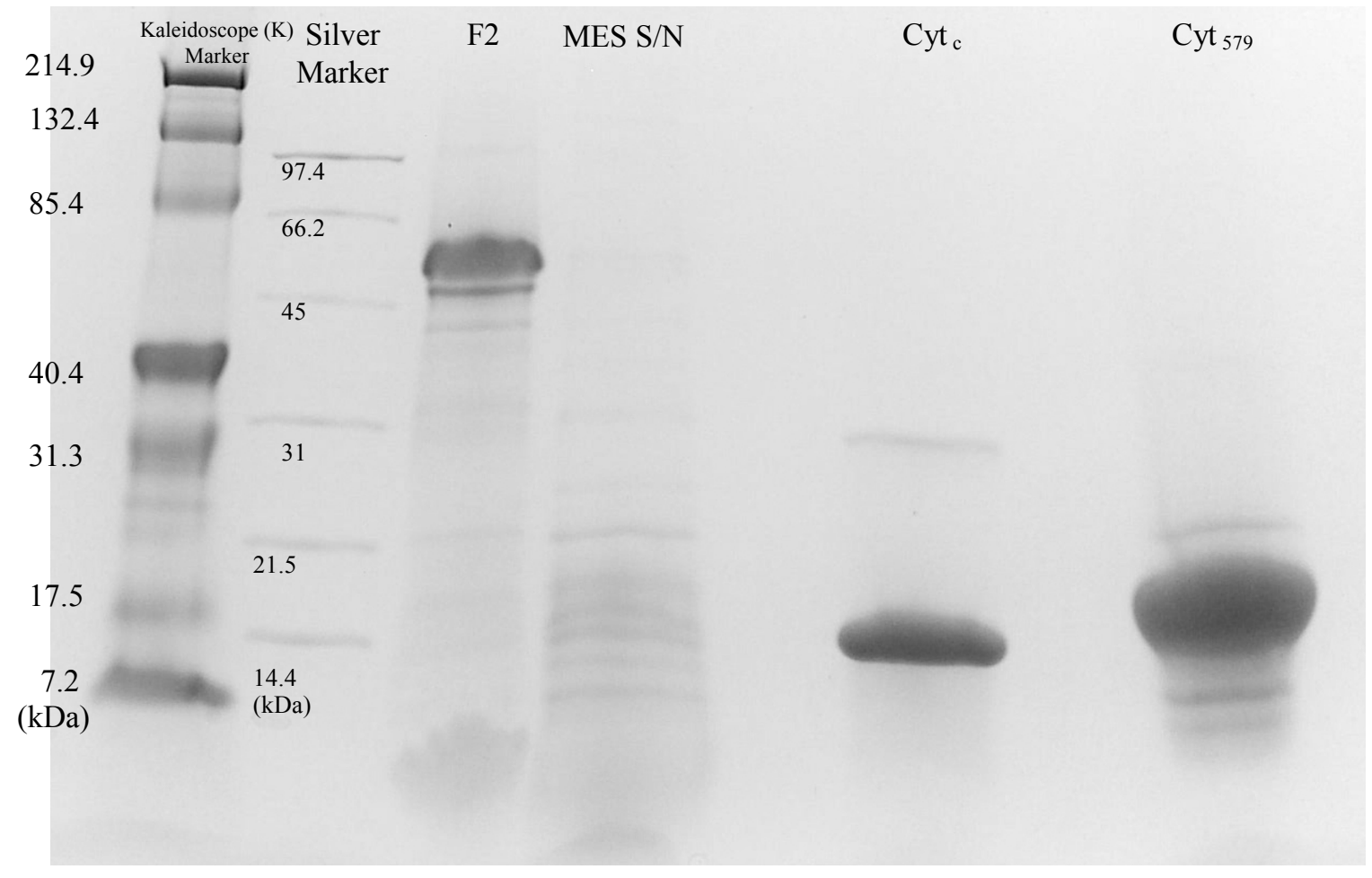

Figure 3a. Imperial Protein stain on 10-20\% polyacrylamide: Heme Group Fluorescence.

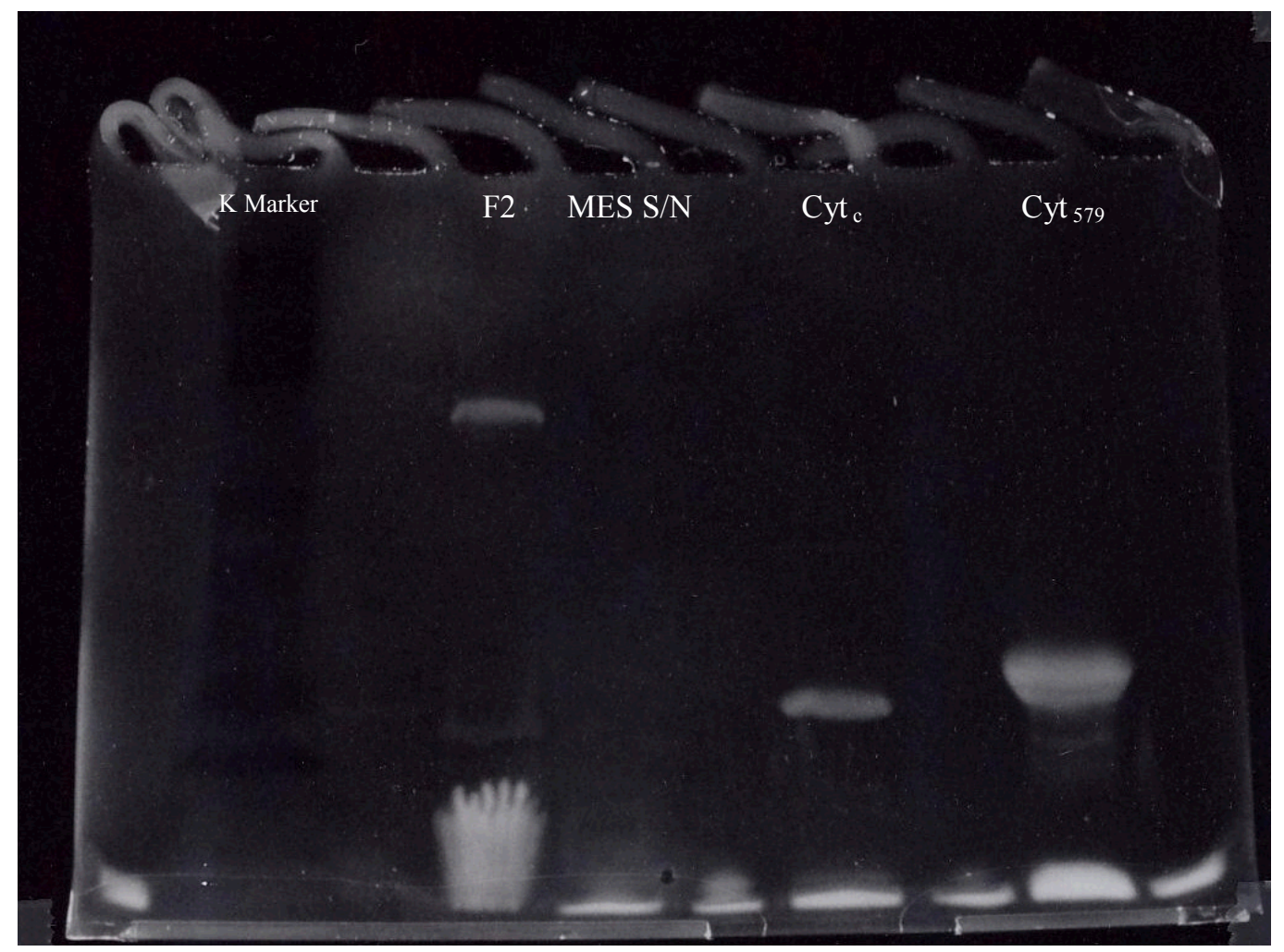

Figure 3b. EtBr stained 10-20\% polyacrylamide: Heme Group Fluorescence 


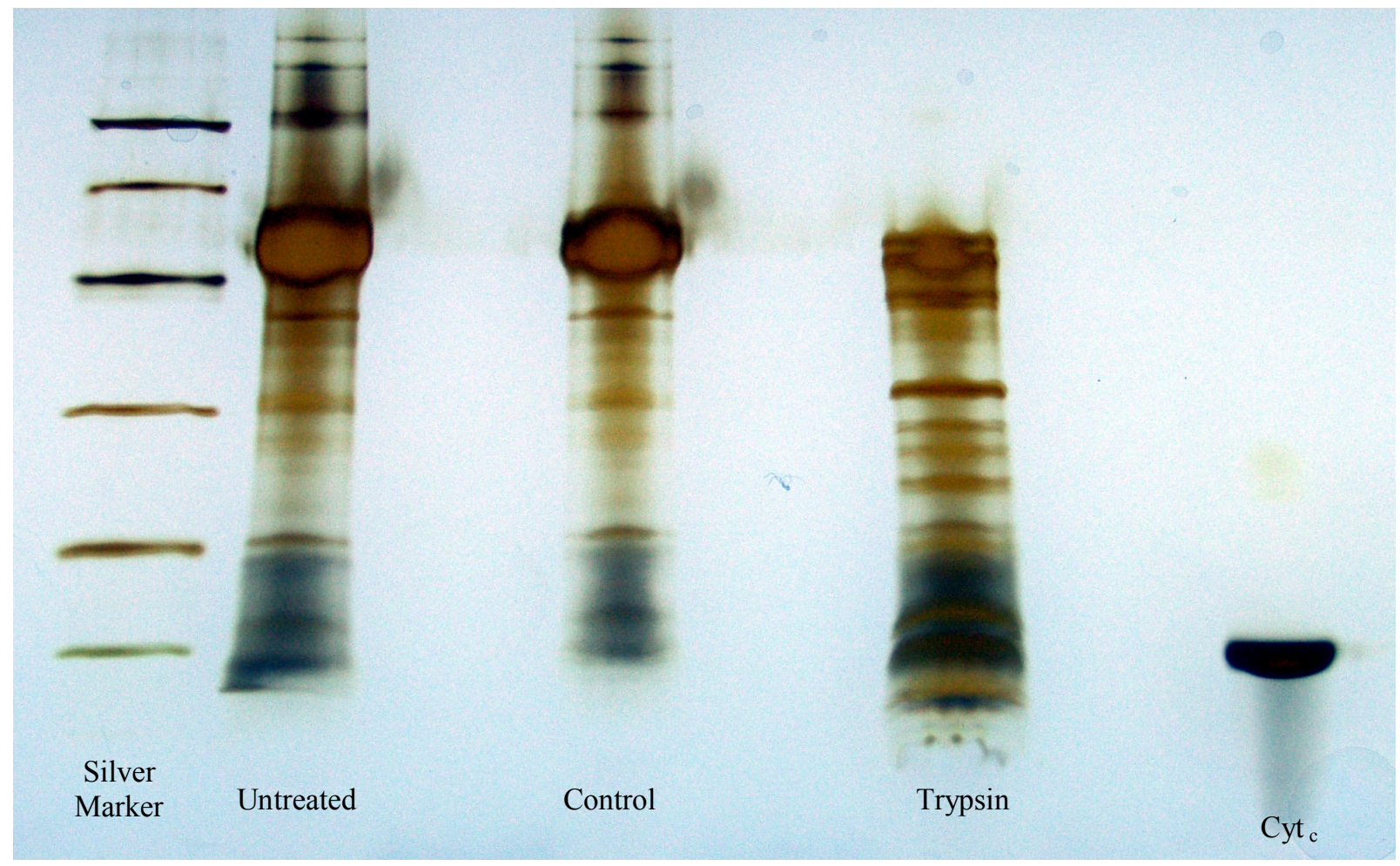

Figure 4a. Silver Stained 10-20\% polyacrylamide gel of Digest 1: Trypsin

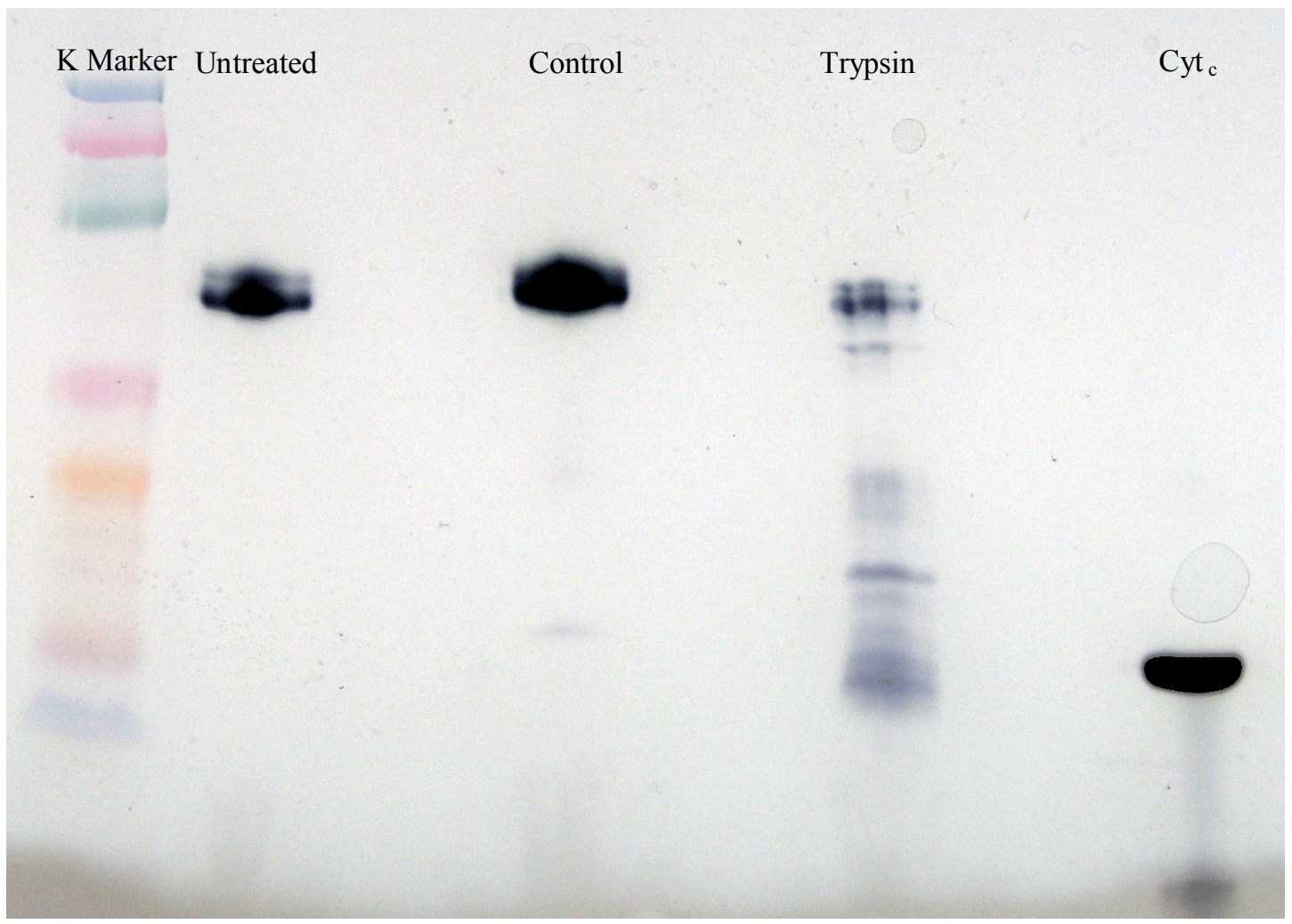

Figure 4b. Heme stained 10-20\% polyacrylamide gel of Digest 1: Trypsin 


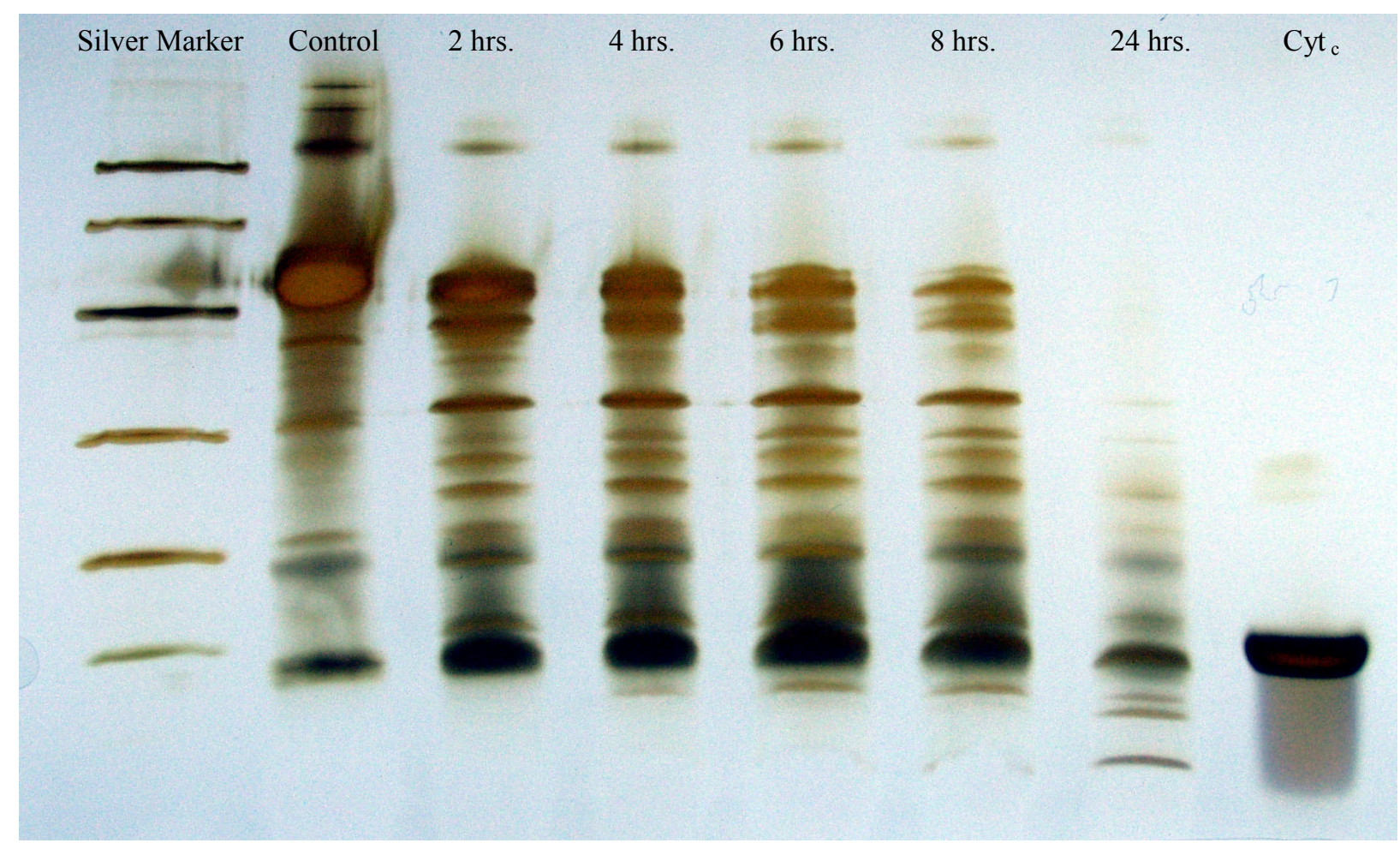

Figure 5a. Silver Stained 10-20\% polyacrylamide gel of Digest 2: Trypsin time profile

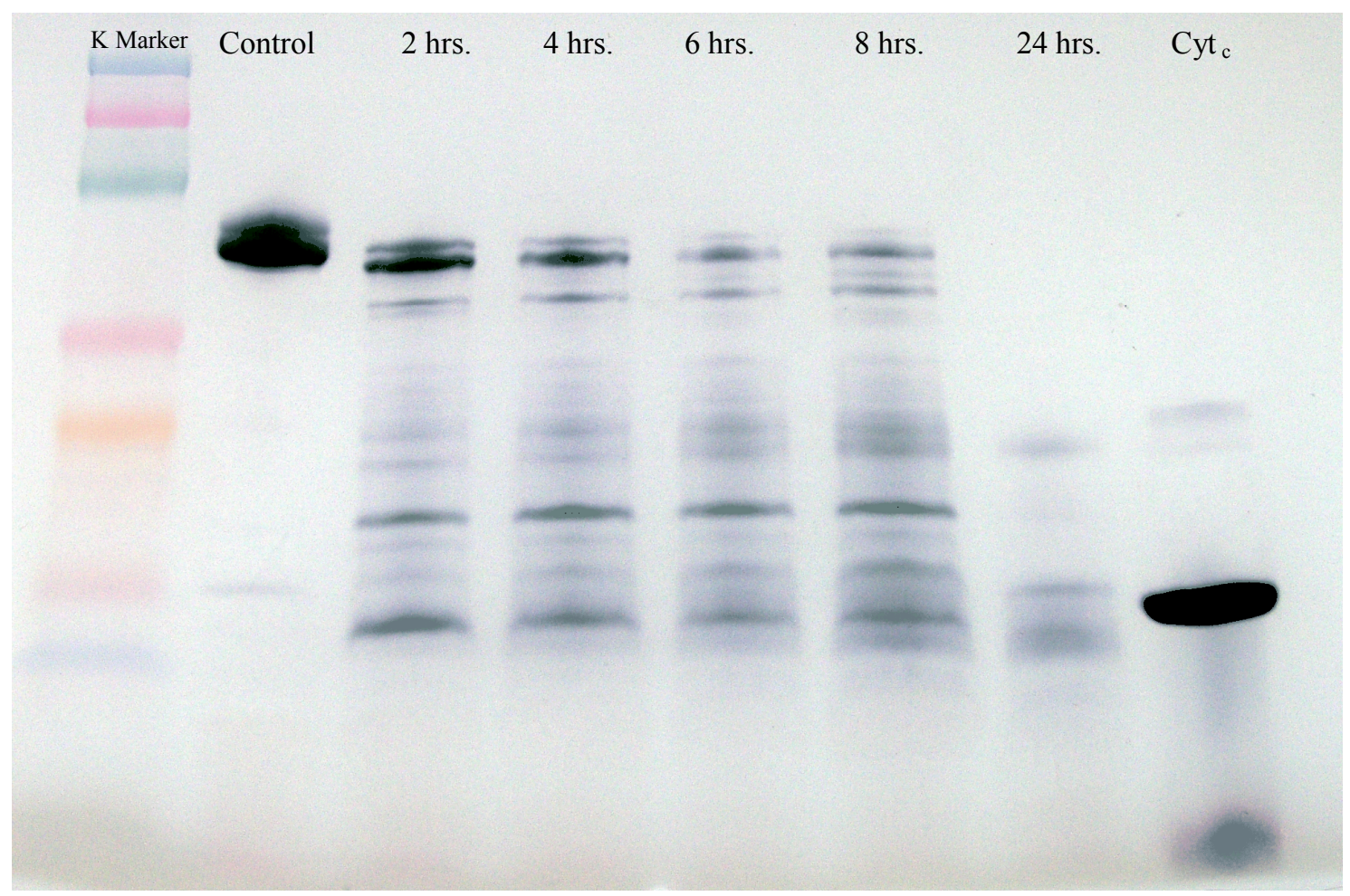

Figure 5b. Heme stained 10-20\% polyacrylamide gel of Digest 2: Trypsin time profile 


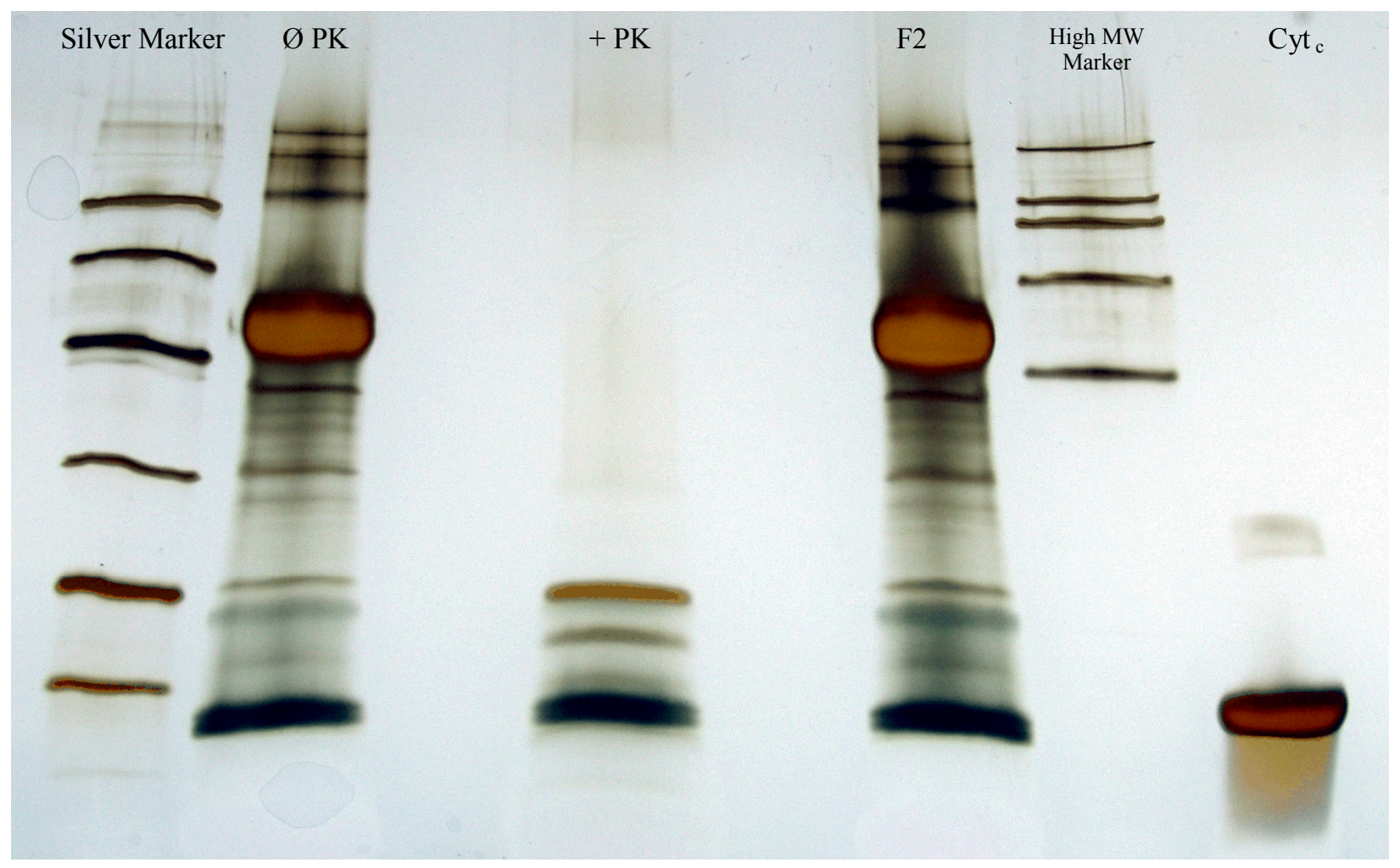

Figure 6a. Silver Stained 10-20\% polyacrylamide gel of Digest 3: Proteinase K

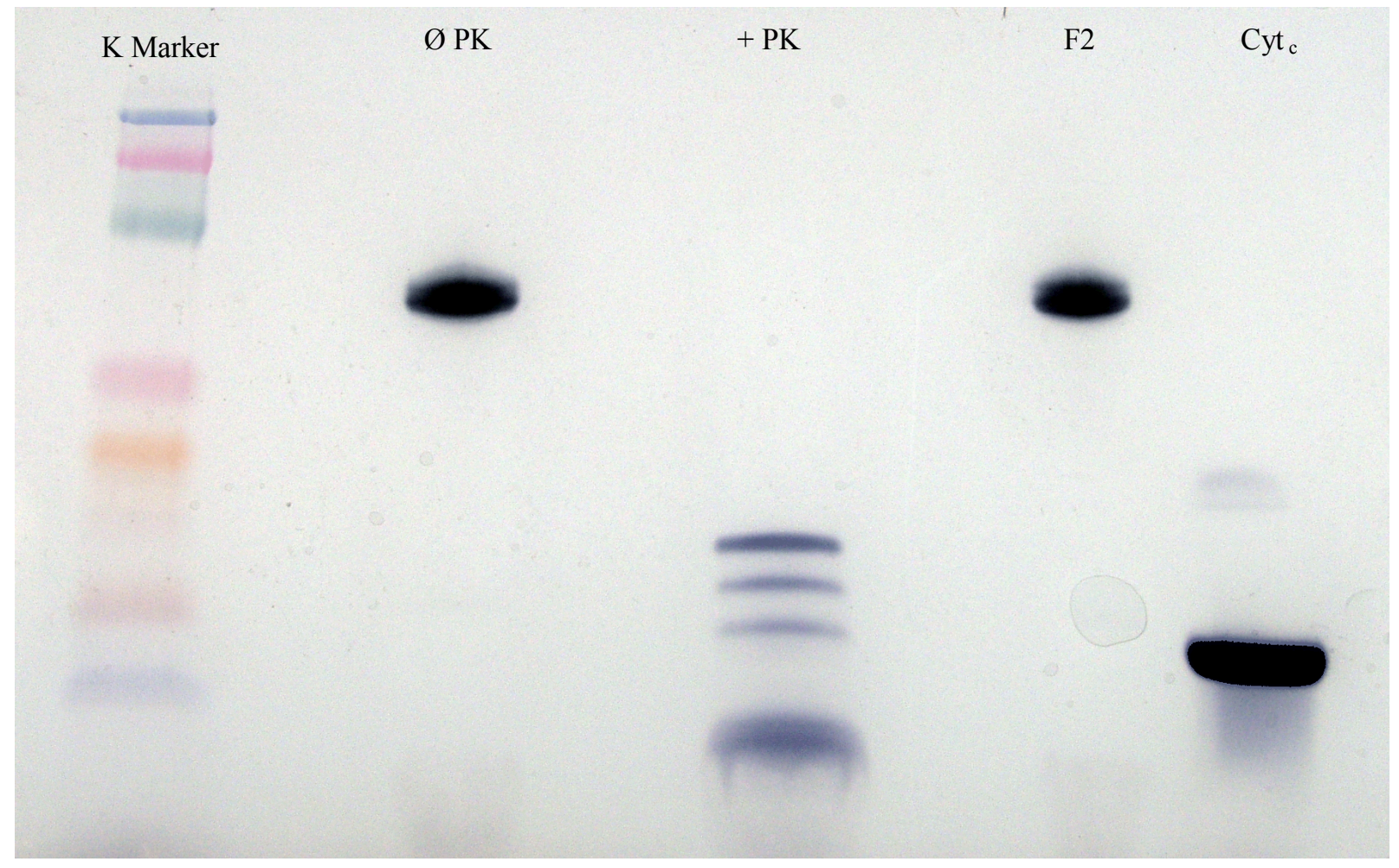

Figure 6b. Heme stained 10-20\% polyacrylamide gel of Digest 3: Proteinase K 


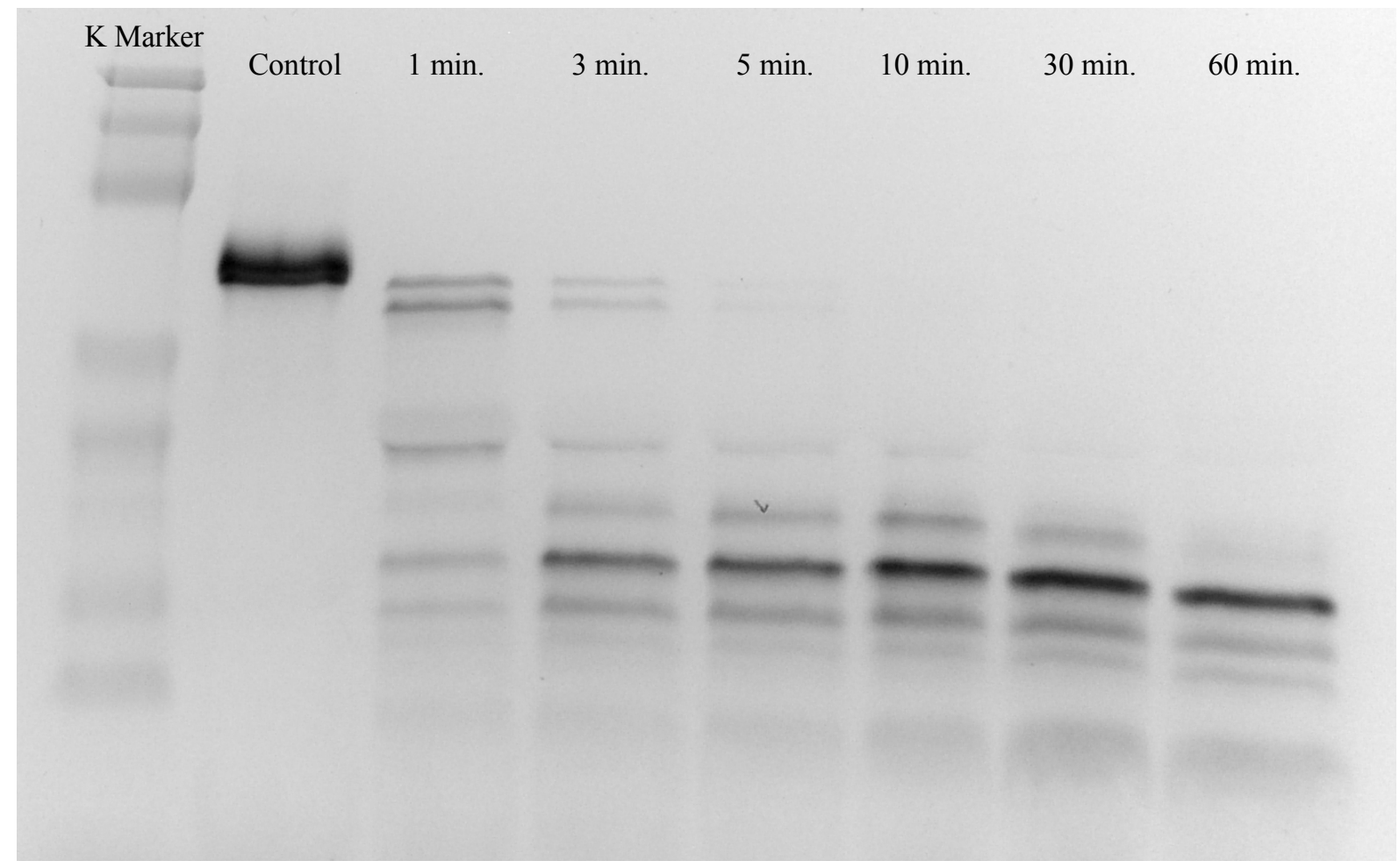

Figure 7. Heme stained 10-20\% polyacrylamide gel of Digest 4: Proteinase K time profile

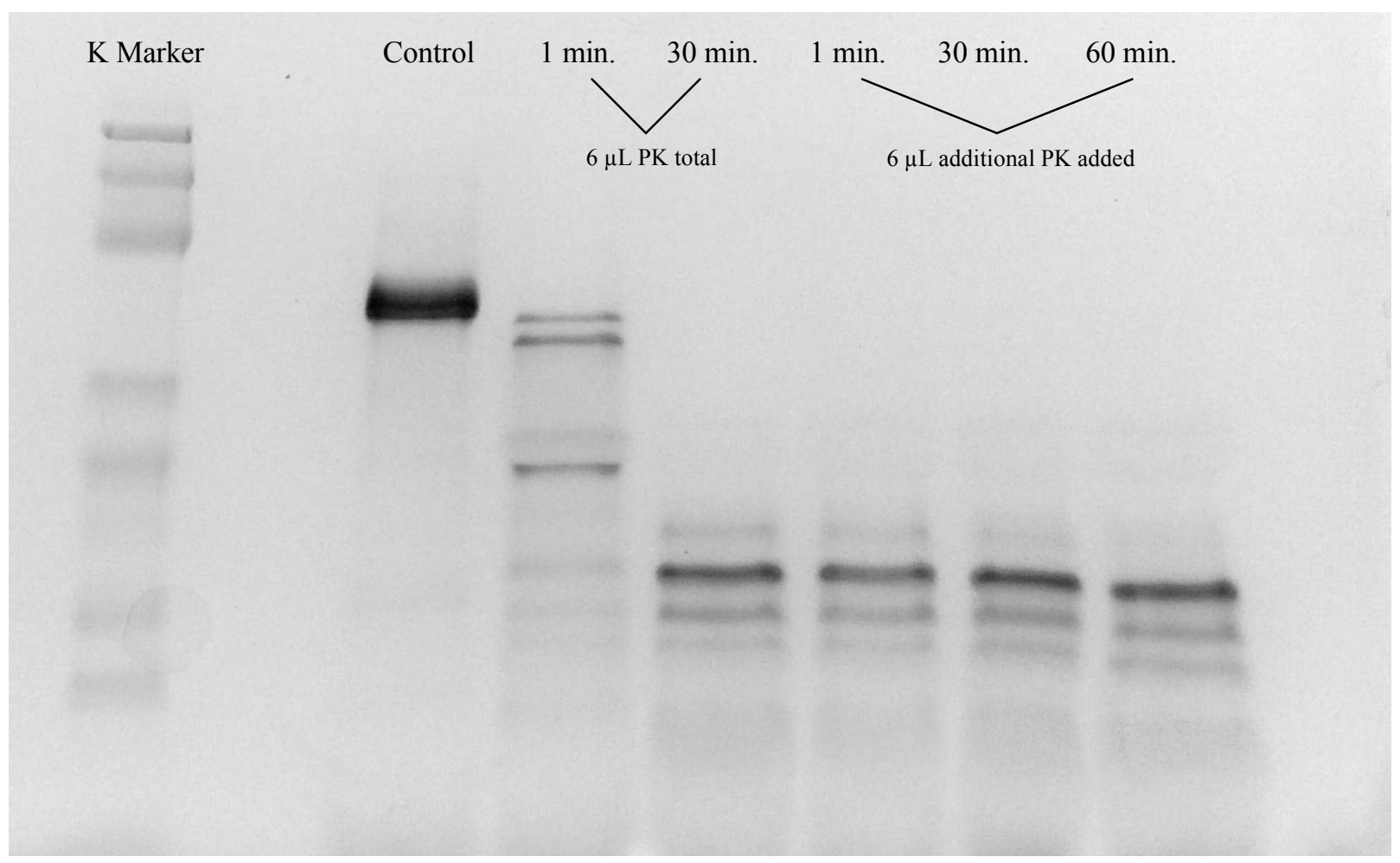

Figure 8. Heme stained 10-20\% polyacrylamide gel of Digest 4: Proteinase time profile with additional PK 


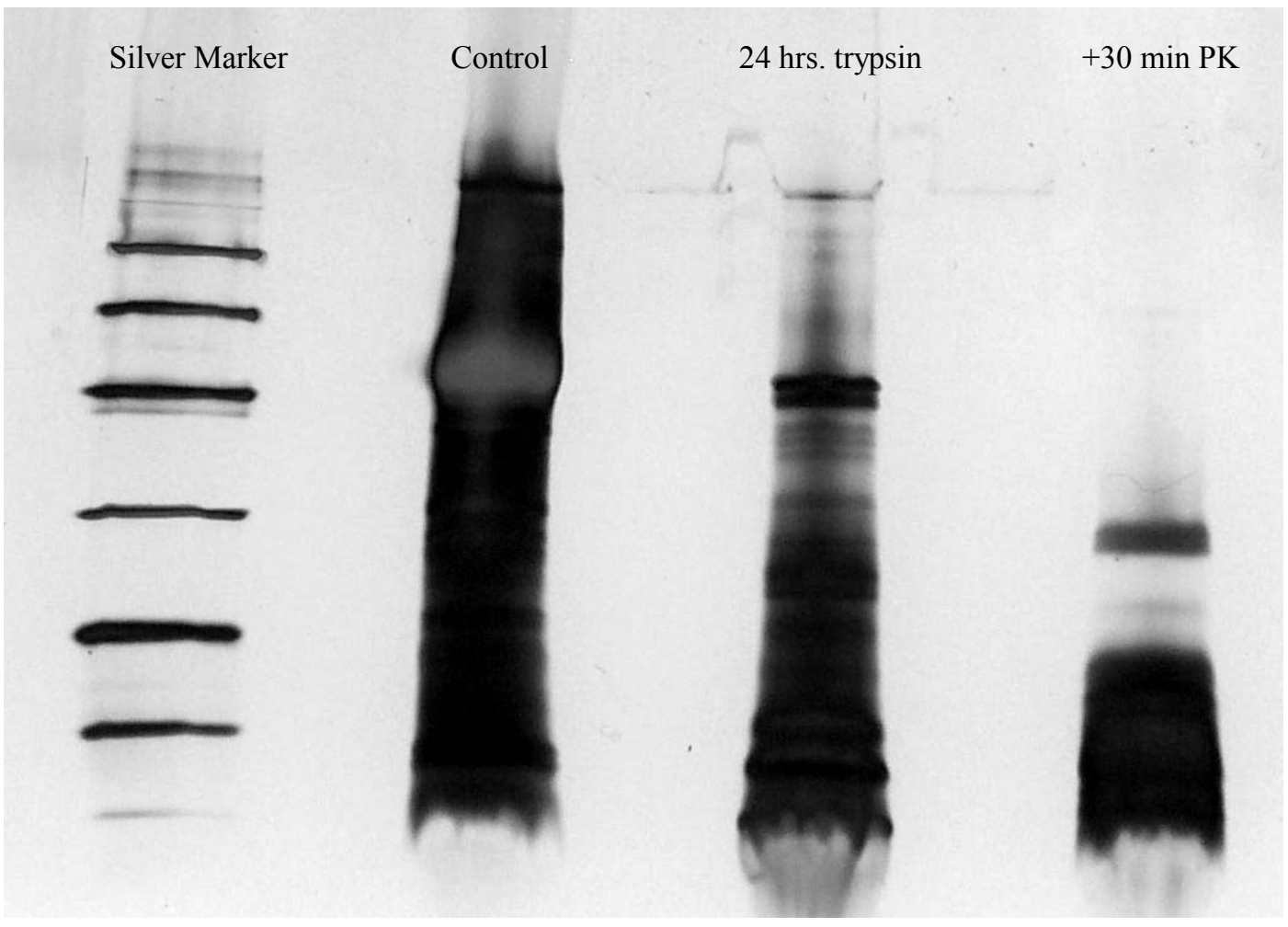

Figure 9a. Silver Stained 10-20\% polyacrylamide gel of Digest 5: Trypsin and Proteinase K

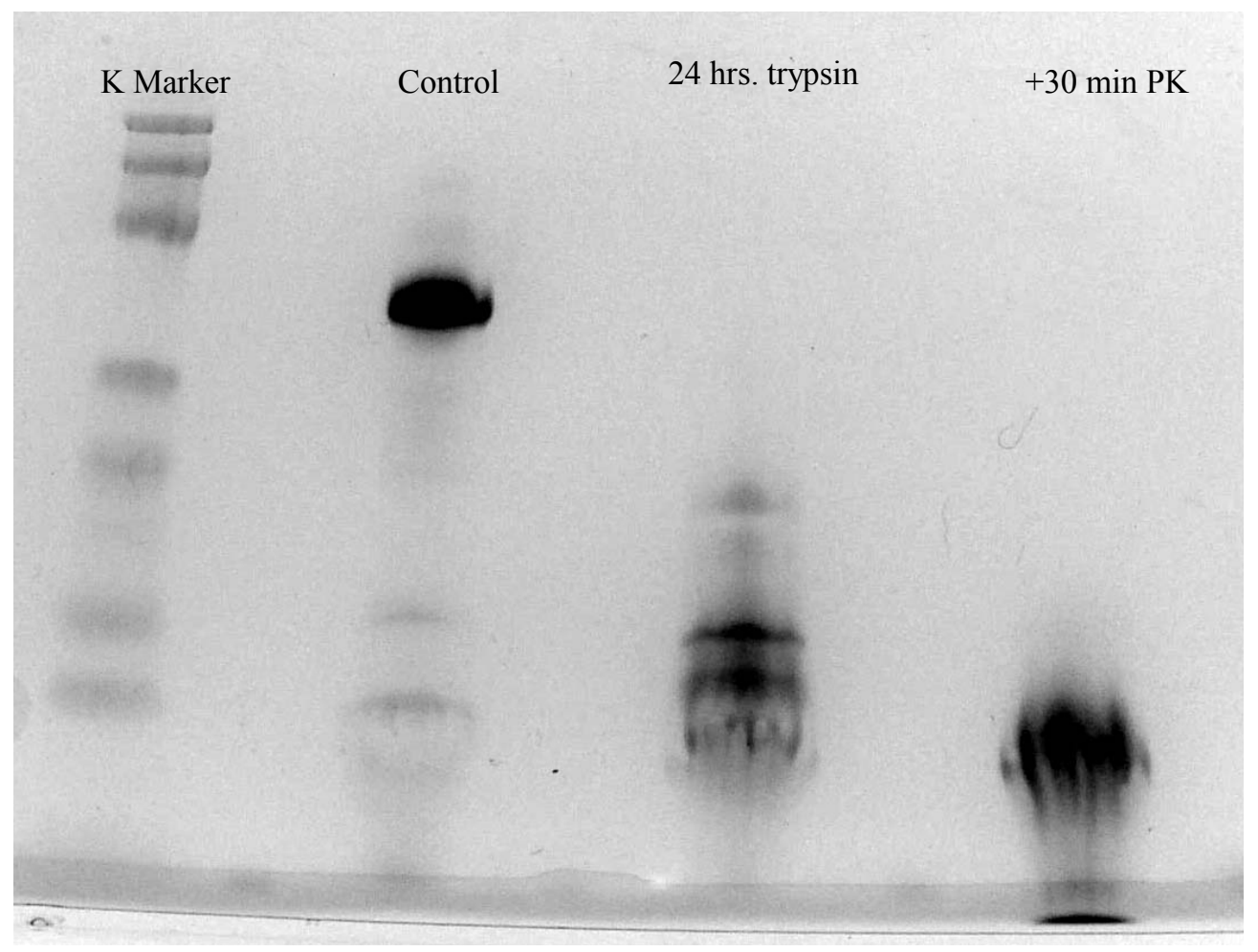

Figure 9b. Heme stained 10-20\% polyacrylamide gel of Digest 5: Trypsin and Proteinase K 